\title{
Stevens-Johnson syndrome and toxic epidermal necrolysis: epidemiological and clinical outcomes analysis in public hospitals*
}

\author{
Luana Bernardes Arantes ${ }^{1}$ \\ Alice Garbi Novaes ${ }^{6}$ \\ Leila Bernarda Donato Göttems ${ }^{4}$
}

\author{
Carmélia Santiago Reis ${ }^{2,3}$ \\ Marta Rodrigues de Carvalho ${ }^{4}$ \\ Maria Rita Carvalho Garbi Novaes ${ }^{3,5}$
}

DOI: http:/ /dx.doi.org/10.1590/abd1806-4841.20176610

\begin{abstract}
BACKGROUND: Adverse drug reactions are harmful and involuntary responses to drugs that occur at doses normally used for a given condition. Among them are Stevens-Johnson syndrome and toxic epidermal necrolysis, both rare and potentially fatal conditions.

Овлестіvеs: To analyze the epidemiological and clinical characteristics related to patients diagnosed with Stevens-Johnson syndrome and toxic epidermal necrolysis in public hospitals in the Federal District - Brazil.

Methods: Retrospective, cross-sectional and descriptive study, in which data were collected referring to patients hospitalized in the public healthcare system of the Federal District from 1999 to 2014. Results: Between 1999 and 2014, 86 cases of hospitalized patients with diagnosis of Stevens-Johnson syndrome and toxic epidermal necrolysis in the Federal District were reported. The majority of patients were women; the most affected age group was 0 to 10 years. Patients older than 60 years (elderly) represent $6.98 \%$ of the cases. Most patients admitted to the referral hospital were discharged. However, occurrence of deaths exceeded that of discharge in elderly patients.

LiMITATIONS OF THE STUDY: There is fragility in the registry of hospitalization of patients, both in the hospital information system and in the medical records of the reference hospital.

CONCLUSION: There is a need for greater production and better dissemination of information on the incidence of adverse drug reactions.
\end{abstract}

Keywords: Drug eruptions; Epidemiology; Stevens-Johnson syndrome

\section{INTRODUCTION}

Ease of access to medicines and their uncontrolled use by population are public health issues, considering their risks, adverse events and toxicity. Negative consequences of drug use and occurrence of adverse events lead to an increase in hospital admissions and deaths. Adverse drug reaction (ADR) can be defined as the harmful and unintended response to a drug, which occurs at doses normally used for prophylaxis, diagnosis or treatment of a disease, or for the modification of a physiological function. ${ }^{1}$

Although skin is the most affected organ, these reactions can occur in other organs such as liver, lungs, bone marrow and kidneys. These reactions are not yet fully understood, but are assumed to have an immunological nature. ${ }^{2}$ As for intensity, ADR may manifest as a mild reaction of little or no clinical relevance, medium or severe, and may cause hospitalization, as well as disabling and lethal sequelae. ${ }^{3}$

ADR may occur in the form of mild skin rashes, which can sometimes be severe and lethal, such as in Stevens-Johnson syndrome (SJS) and toxic epidermal necrolysis (TEN). ${ }^{4}$ In SJS, body surface area affected does not exceed $10 \% .{ }^{5}$ Cutaneous detachment between $10 \%$ and $30 \%$ characterizes a transition zone between SJS and TEN. Epidermis detachment superior to $30 \%$ characterizes TEN, also known as Lyell's syndrome. ${ }^{6}$

SJS and TEN are rare conditions, with an estimated incidence of 1.2-6 cases/million inhabitants and 0.4-1.2 cases/million inhabitants, respectively, and are some of the few dermatological entities that constitute a medical emergency. ${ }^{7,8}$ In Europe, it is estimat-

Received on 15.10 .2016 .

Approved by the Advisory Board and accepted for publication on 03.04.2017.

Study conducted at Hospital de Referência em Queimados no Distrito Federal - Hospital Regional da Asa Norte (HRAN) and Secretaria de Saúde do Distrito Federal (SES-DF) - Brasília (DF), Brazil.

Financial support: National Council for Scientific and Technological (CNPq) and Foundation for Teaching and Research in Health Sciences (FEPECS/SES-DF). Conflict of interest: None.

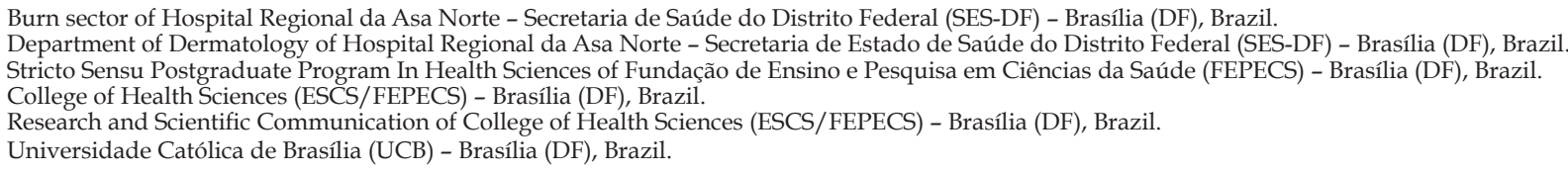


ed that ADRs account for 3\% to $8 \%$ of hospital admissions among all individuals seeking care. Among the elderly, ADRs account for $17 \%$ of hospital admissions. It was found in England that $6.5 \%$ of the annual admissions in hospital emergencies happened due to ADR. It is estimated that prevalence of mortality due to ADRs in general population is approximately $0.15 \% .{ }^{4}$ In Brazil, prevalence data are scarce. ${ }^{9}$ Commonly, fever and malaise are the first symptoms of severe ADRs, which may persist or even increase when lesions appear. They are characterized by cutaneous erythema with formation of blisters and hemorrhagic erosions of mucous membranes, such as stomatitis, balanitis, colpitis, severe conjunctivitis and blepharitis. ${ }^{10}$ Despite severity of these conditions, especially TEN, there is still no consensus on the most appropriate management of patients, and there is great variability in the management of patients with SJS and TEN. Basis of treatment involves discontinuation of the offending agent, as well as supportive care. ${ }^{11,12}$

In order to evaluate prognosis of patients affected by SJS and TEN, there is a score that measures severity of cases (SCORTEN) and that must be performed within the first 48 hours of the disease. SCORTEN is composed of 7 parameters: age $>40$ years; neoplasms; tachycardia (>120 bpm); epidermal detachment $>10 \%$; serum urea $>10 \mathrm{mmol} / \mathrm{l}$; serum glucose $>14 \mathrm{mmol} / \mathrm{l}$ (approximately $252 \mathrm{mg}$ / $\mathrm{dl})$; and serum bicarbonate $\leq 20 \mathrm{mmol} / \mathrm{l}$. These parameters determine a better or worse prognosis of the patient. For each of these items, 1 point is given if the item is present or 0 point if the item is absent. When the patient scores 3 or more, he/she should be managed in an intensive care unit. A score $\geq 5$ predicts a mortality rate of approximately $90 \%{ }^{6}$ Risk of death is higher in the elderly and in those with larger affected body surface..$^{13}$

The aim of this study is to analyze epidemiological and clinical characteristics related to patients diagnosed with SJS and TEN in public hospitals in the Federal District - Brazil.

\section{METHODS}

This is a retrospective, cross-sectional and descriptive study, in which data were collected referring to patients hospitalized at the referral hospital for the treatment of the aforementioned diseases and in other hospitals of the public healthcare system of the Federal District from 1999 to 2014. For this, a survey was conducted in the Hospital Inpatient System (SIH) of hospitalized patients with the following ICDs: L51; L51.0; L51.1; L51.2; L51.8; and L51.9, related to SJS and TEN in this period.

Data obtained by SIH survey included age, sex, year of hospitalization, days of hospitalization and hospital. There were no more detailed clinical records, such as severity classification, treatment, complications, or clinical outcome.

Regarding patients admitted to the referral hospital, in addition to data collected by SIH, clinical data were also added, such as SJS or TEN classification, percentage of affected body surface, suspected drug to trigger the syndrome, treatment, complications, and clinical outcome from medical charts and records books. Drugs suspected of causing the reactions were selected based on the degree of medical suspicion described in medical record and classified according to the Anatomical Therapeutic Chemical (ATC) developed by the World Health Organization (WHO). ${ }^{14}$
All data were organized in Microsoft Excel software, version 2013, and IBM SPSS 21, and analyzed using descriptive statistics.

Thus, data were demonstrated in two groups: patients admitted to the public healthcare system and patients hospitalized at the reference healthcare unit. We also performed a specific analysis of elderly patients in both groups.

The research project was approved by the Research Ethics Committee of the Fundação de Ensino e Pesquisa em Ciências da Saúde, Secretaria Estadual de Saúde, DF, (CEP/FEPECS), CAEEE: 18587713.7.0000.5553. Secrecy and confidentiality of data collected in patients' records were preserved.

\section{RESULTS}

Between 1999 and 2014, there were 86 cases of hospitalized patients diagnosed with SJS and TEN in the Federal District. The highest number of cases was recorded in 2000 and 2001, and in 2004, the lowest number of cases was recorded. In 2008, there was no case recorded by $\mathrm{SIH}$, as it can be observed in table 1 .

Of the total number of cases registered, most of patients were women, representing 47 cases of the total recorded. It can be verified that the most affected age group was 0 to 10 years. Mean age of patients was 23 years, ranging from 47 days to 72 years. Patients aged $>60$ years (elderly) accounted for $6.98 \%$ of cases.

There were hospitalizations in 12 public hospitals of the Secretaria Estadual de Saúde do Distrito Federal, in addition to cases registered at the Hospital Universitário de Brasilia (HUB). Most of patients had their hospitalization recorded at Hospital Regional da Asa Norte (HRAN), a reference hospital for the treatment of SJS and TEN (Table 2).

Patients' hospitalization time ranged from 1 to 72 days, with a mean of 10 days. Most patients were hospitalized for less than 10 days in total. One patient was hospitalized for over 40 days (Table 2).

Regarding specific data of patients hospitalized in the reference unit, the majority were women. Predominant age group was 30 to 40 years (Table 3). Older patients accounted for $29.29 \%$ of the total observed in this hospital, and the majority was also women.

Data regarding clinical outcome showed that majority of patients admitted to the referral hospital were discharged. However, if we consider only the elderly population, occurrence of deaths exceeded the occurrence of discharged $(66.67 \%$ of elderly patients died). There is no record in medical charts regarding outpatient follow-up of patients who were discharged.

Regarding affected body surface, with data obtained in medical records, classification of severity was made, according to Harr's indication (Table 4). ${ }^{8}$

However, such classification is not used in the treatment unit. According to the diagnosis recorded in the medical chart, percentage of patients diagnosed with TEN was $52.17 \%$, but there was no record of patient with an affected body surface area $<30 \%$, which differs from the suggested classification.

Drugs considered suspected to trigger SJS and TEN were grouped according to their classification, considering also the number of times they were cited in the medical record, since the same patient can use more than one medication concomitantly. Anticonvulsants accounted for the majority of those responsible for the oc- 
TABLE 1: Incidence by year, classification by sex and age group of Stevens-Johnson syndrome cases and toxic epidermal necrolysis attended in the Federal District, Brazil. Period: 1999 to 2014

\begin{tabular}{|c|c|c|c|c|c|c|c|c|c|c|c|c|c|}
\hline \multirow[t]{2}{*}{ YEAR } & \multirow{2}{*}{$\begin{array}{c}\text { ASSISTED } \\
\text { CASES }\end{array}$} & \multicolumn{2}{|c|}{ SEX } & \multicolumn{10}{|c|}{ AGE GROUP } \\
\hline & & $\mathrm{F}$ & $\mathrm{M}$ & $00-10$ & $10-20$ & $20-30$ & $30-40$ & $40-50$ & $50-60$ & $60-70$ & $70-80$ & $>$ & 80 \\
\hline 1999 & 3 & 1 & 2 & 1 & - & - & 1 & 1 & - & - & - & & - \\
\hline 2000 & 10 & 6 & 4 & 3 & 1 & 3 & 1 & 1 & - & 1 & - & & - \\
\hline 2001 & 10 & 6 & 4 & 3 & 2 & - & 1 & 3 & 1 & - & - & & - \\
\hline 2002 & 7 & 4 & 3 & 4 & 1 & 1 & - & 1 & - & - & - & & - \\
\hline 2003 & 3 & 1 & 2 & 2 & - & - & - & - & 1 & - & - & & - \\
\hline 2004 & 2 & - & 2 & 1 & - & - & 1 & - & - & - & - & & - \\
\hline 2005 & 3 & 2 & 1 & 2 & - & - & - & - & - & - & 1 & & - \\
\hline 2006 & 4 & 2 & 2 & 4 & - & - & - & - & - & - & - & & - \\
\hline 2007 & 3 & 2 & 1 & 3 & - & - & - & - & - & - & - & & - \\
\hline 2008 & - & - & - & - & - & - & - & - & - & - & - & & - \\
\hline 2009 & 8 & 5 & 3 & 3 & 3 & 1 & - & - & - & 1 & - & & - \\
\hline 2010 & 8 & 5 & 3 & 4 & 2 & - & - & 1 & 1 & - & - & & - \\
\hline 2011 & 6 & 3 & 3 & - & 2 & - & 3 & 1 & - & - & - & & - \\
\hline 2012 & 7 & 5 & 2 & 3 & - & 2 & - & - & 2 & - & - & & - \\
\hline 2013 & 5 & 4 & 1 & 2 & - & 1 & 1 & - & - & 1 & - & & - \\
\hline 2014 & 7 & 1 & 6 & 3 & - & - & 1 & 2 & - & 1 & - & & - \\
\hline TOTAL & 86 & 47 & 39 & 38 & 11 & 8 & 9 & 10 & 5 & 4 & 1 & & - \\
\hline
\end{tabular}

TABLE 2: Number of cases per hospital and mean time of hospitalization for Stevens-Johnson syndrome and toxic epidermal necrolysis in the Federal District, Brazil. Period: 1999 to 2014

\begin{tabular}{|c|c|c|c|c|c|c|c|c|c|c|c|c|c|c|c|c|c|c|c|}
\hline \multirow[t]{2}{*}{ YEAR } & \multicolumn{14}{|c|}{ HOSPITALS } & \multicolumn{5}{|c|}{ MEAN HOSPITALIZATION TIME (DAYS) } \\
\hline & $\begin{array}{l}\text { 耑 } \\
\text { 至 }\end{array}$ & 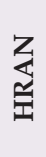 & 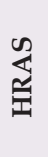 & 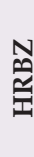 & U & $\begin{array}{l}\text { U } \\
\widetilde{\Xi}\end{array}$ & $\begin{array}{l}\text { 己 } \\
\cong \\
\text { I }\end{array}$ & 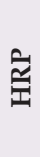 & $\underline{\underline{z}}$ & 号 & 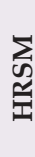 & 点 & $\underbrace{\infty}_{\text {光 }}$ & 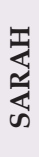 & $\begin{array}{l}\circ \\
\stackrel{1}{1} \\
0\end{array}$ & 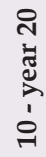 & $\begin{array}{l}\text { ले } \\
1 \\
\text { ते }\end{array}$ & $\begin{array}{l}\text { 암 } \\
\text { 'ं }\end{array}$ & $\begin{array}{l}\text { 아 } \\
\wedge\end{array}$ \\
\hline 1999 & - & 2 & - & - & - & 1 & - & - & - & - & - & - & - & - & 1 & 2 & - & - & - \\
\hline 2000 & - & 2 & 1 & 1 & - & 2 & - & - & - & 4 & - & - & - & - & 6 & 2 & - & 1 & 1 \\
\hline 2001 & 1 & 3 & - & - & - & 4 & - & 1 & - & - & - & - & 1 & - & 8 & 1 & 1 & - & - \\
\hline 2002 & - & 2 & 3 & - & - & - & - & 1 & - & - & - & - & 1 & - & 5 & 1 & 1 & - & - \\
\hline 2003 & - & - & 2 & - & - & - & - & - & - & - & - & - & - & 1 & 1 & 2 & - & - & - \\
\hline 2004 & - & - & 1 & - & - & - & - & 1 & - & - & - & - & - & - & 2 & - & - & - & - \\
\hline 2005 & - & - & 2 & - & - & - & - & - & - & 1 & - & - & - & - & 2 & 1 & - & - & - \\
\hline 2006 & - & - & 3 & - & - & - & - & - & - & - & - & - & 1 & - & 4 & - & - & - & - \\
\hline 2007 & - & - & 2 & 1 & - & - & - & - & - & - & - & - & - & - & 3 & - & - & - & - \\
\hline 2008 & - & - & - & - & - & - & - & - & - & - & - & - & - & - & - & - & - & - & - \\
\hline 2009 & 2 & - & - & - & 2 & - & - & - & - & - & - & 1 & 3 & - & 7 & - & - & 1 & - \\
\hline 2010 & 1 & 1 & - & - & - & - & 1 & - & - & - & - & 5 & - & - & 6 & 2 & - & - & - \\
\hline 2011 & - & 4 & - & - & - & - & - & - & - & - & - & 2 & - & - & 4 & 2 & - & - & - \\
\hline 2012 & - & 6 & - & - & - & - & - & - & - & - & - & 1 & - & - & 4 & 2 & 1 & - & - \\
\hline 2013 & 2 & 1 & - & - & - & - & - & - & 1 & - & - & 1 & - & - & 4 & 1 & - & - & - \\
\hline 2014 & - & - & - & - & 1 & - & - & 1 & 1 & - & 1 & 3 & - & - & 5 & 2 & - & - & - \\
\hline TOTAL & 6 & 21 & 14 & 2 & 3 & 7 & 1 & 4 & 2 & 5 & 1 & 13 & 6 & 1 & 62 & 18 & 3 & 2 & 1 \\
\hline
\end{tabular}


currences, followed by analgesics and antibiotics. There is no information whether such medications were prescribed or whether they were self-medicated (Table 5).

On treatment, most patients received systemic antibiotic ther- apy, wound dressings, and suspension of suspected drug. The most frequent complications were infection of lesions, sepsis and severe ocular lesion. There were no complications in $21 \%$ of the cases (Table 6).

TABLE 3: Age group of patients with Stevens-Johnson syndrome and toxic epidermal necrolysis attended at the referral hospital of the Federal District, Brazil. Period: 1999 to 2014

\begin{tabular}{lcccccccccccccc} 
SEX & \multicolumn{1}{c}{ AGE GROUP } & \multicolumn{2}{c}{ TOTAL } \\
\cline { 2 - 12 } & $0-10$ & $10-20$ & $20-30$ & $30-40$ & $40-50$ & $50-60$ & $60-70$ & $70-80$ & $>0$ \\
\hline WOMEN & 0 & 3 & 2 & 4 & 0 & 1 & 1 & 1 & 0 & 12 \\
MEN & 0 & 2 & 1 & 3 & 2 & 0 & 1 & 0 & 0 & 9
\end{tabular}

TABLE 4: Body surface affected in patients with Stevens-Johnson syndrome and toxic epidermal necrolysis at the referral hospital in the Federal District, Brazil. Period: 1999 to 2014

\begin{tabular}{|c|c|c|}
\hline \multicolumn{2}{|c|}{ BBS* } & \multirow{2}{*}{$\begin{array}{c}\text { NUMBER OF CASES } \\
0\end{array}$} \\
\hline UNTIL $10 \%$ & (SJS) & \\
\hline $10 \%-30 \%$ & (OVERLAPPING) & 3 \\
\hline$>30 \%$ & $(\mathrm{TEN})$ & 16 \\
\hline & ORMED & 2 \\
\hline
\end{tabular}

*The name used in the medical record refers to the burned body surface, used in the burned patient treated in the care unit based on Wallace rule of nines. Source: Dodiuk-Gad RP, et al. 2015

TABLE 5: Drugs associated with Stevens-Johnson syndrome and toxic epidermal necrolysis in patients assisted at the referral hospital in the Federal District, Brazil. Period: 1999 to 2014

Pharmaceutical group according to the classification Suspected drugs according to anatomical therapeutic anatomical therapeutic chemical (atc)

N02 - ANALGESICS

chemical (atc)

J01 - ANTIBIOTICS

N03 - ANTICONVULSANTS

DIPYRONE (N02BB02)

AMOXICILLIN (J01CA04)

AMOXICILLIN + POTASSIUM CLAVULANATE (J01CR02)

AZITROMYCIN (J01FA10)

ERYTHROMYCIN (J01FA01)

LEVOFLOXACIN (J01MA12)

PENICILLIN BENZATINE (J01CE08)

SULFADIAZINE (J01EC02)

SULFAMETOXAZOLE + TRIMETHOPRIM (J01EE01)

CARBAMAZEPINE (N03AF01)

PHENYTOIN (N03AB02)

PHENOBARBITAL (N03AA02)

LAMOTRIGINE (N03AX09)

N06AA - TRICYCLIC ANTIDEPRESSANT

AMITRIPTILINE CHLORIDRATE (N06AA09)

N02B - ANALGESIC AND ANTIPYRETIC

RESFENOL (N02BE51)

ENALAPRIL (C09AA02)

C02 - ANTI-HYPERTENSIVE

METHYLDOPA (C02AB)

BENZYDAMINE HYDROCHLORIDE (M01AX07. M02AA05)

Percentage

M01 - ANTI-INFLAMMATORY

DICLOFENAC (M01AB05)

IBUPROFEN (M01AE01)

TALIDOMIDE (L04AX02)

LAMIVUDINE (J05AF05)

J05 - ANTIRRETROVIRAL

FENOTEROL (R03AC04)

R03 - BRONCHODILATOR

CINNARIZINE (N07CA02)

N07 - ANTIVERTIGINOUS

\begin{tabular}{|c|c|}
\hline 5 & of total \\
\hline 2 & $23.8 \%$ \\
\hline 1 & $9.52 \%$ \\
\hline 1 & $4.76 \%$ \\
\hline 2 & $4.76 \%$ \\
\hline 1 & $9.52 \%$ \\
\hline 2 & $4.76 \%$ \\
\hline 1 & $9.52 \%$ \\
\hline 1 & $4.76 \%$ \\
\hline 4 & $4.76 \%$ \\
\hline 2 & $19.04 \%$ \\
\hline 6 & $9.52 \%$ \\
\hline 1 & $28.57 \%$ \\
\hline 1 & $4.76 \%$ \\
\hline 1 & $4.76 \%$ \\
\hline 1 & $4.76 \%$ \\
\hline 1 & $4.76 \%$ \\
\hline 1 & $4.76 \%$ \\
\hline 1 & $4.76 \%$ \\
\hline 1 & $4.76 \%$ \\
\hline 1 & $4.76 \%$ \\
\hline 1 & $4.76 \%$ \\
\hline 1 & $4.76 \%$ \\
\hline 1 & $4.76 \%$ \\
\hline
\end{tabular}


TABLE 6: Treatment of patients with Stevens-Johnson syndrome and toxic epidermal necrolysis assisted at the referral hospital of the Federal District, Brazil. Period: 1999 to 2014

\begin{tabular}{|c|c|c|}
\hline TREATMENT & USE OF TREATMENT IN CASES & PERCENTAGE OF TOTAL \\
\hline FOLLOW-UP BY OPHTHALMOLOGY & 1 & $4.3 \%$ \\
\hline ALBUMIN & 1 & $4.3 \%$ \\
\hline ANESTHESIA & 1 & $4.3 \%$ \\
\hline SYSTEMIC ANTIBIOTIC THERAPY & 16 & $69.6 \%$ \\
\hline ANTIHISTAMINICS & 1 & $4.3 \%$ \\
\hline CLEXANE & 1 & $4.3 \%$ \\
\hline EYE DROPS & 3 & $13.0 \%$ \\
\hline DRESSING & 21 & $91.3 \%$ \\
\hline BLOOD PRODUCTS & 3 & $13.0 \%$ \\
\hline IMMUNOGLOBULIN & 1 & $4.3 \%$ \\
\hline CIPROFLOXACIN + HYDROCORTISONE & 1 & $4.3 \%$ \\
\hline OPHTHALMIC OINTMENT & 1 & $4.3 \%$ \\
\hline PREDNISONE & 1 & $4.3 \%$ \\
\hline ANTITETANIC PROPHYLAXIS & 7 & $30.4 \%$ \\
\hline ANTICONVULSIVANTES REPLACEMENT & 4 & $17.4 \%$ \\
\hline SUSPENSION OF MEDICINES & 5 & $21.7 \%$ \\
\hline ICU & 1 & $4.3 \%$ \\
\hline
\end{tabular}

\section{DISCUSSION}

Heterogeneity of studies found and scarcity of epidemiological data indicate that greater production and better dissemination of information on incidence of ADR are necessary, especially in its more severe forms, allowing greater capacity for prevention, diagnosis and treatment. Recent advances have been made due to pharmacogenetic studies, which associate certain alleles of Human Leukocyte Antigens (HLA) with the susceptibility to develop SJS/ TEN in response to various drugs. ${ }^{15}$

When tracing an overview of patients suffering from such diseases hospitalized in the Federal District, we observed that the majority were women, with a predominant age group between 0 and 10 years. Profile of patients admitted to this hospital follows the general picture, comprised mostly by female patients. However, in this case, the predominant age group was between 30 and 40 years.

Data from the literature indicate that the incidence increases between 11 and 20 years of age, which differs from that found in this study. ${ }^{16}$ Number of elderly patients hospitalized corresponds to $6.98 \%$ of the total number of registered cases $(n=86)$. Risk factors for developing SJS/TEN are known to be HIV infection, female gender, and specific HLA types. ${ }^{17}$

Mean time of hospitalization was 10 days, with only one patient hospitalized over 40 days. There is no information in the system regarding clinical outcome of these hospitalizations or severity of recorded cases, making it difficult to define a reliable epidemiological profile to the local reality. Most patients were admitted to the referral hospital for treatment of burns, since patients affected by SJS and TEN acquired a similar appearance to that of a large burned, demanding specialized treatment. ${ }^{16}$
Differentiation of SJS and TEN diagnosis in medical charts studied was not adequately conducted by the professionals who first approached the patients, since diagnosis present in medical records, in most cases, did not coincide with diagnosis made through the classification already adopted. ${ }^{6}$

Most patients attended had a favorable clinical outcome, with hospital discharge. However, deaths surpassed discharged in the elderly population hospitalized. According to the literature, elderly population has a greater predisposition to the occurrence of adverse drug reactions. A study conducted in Asia showed that the second most affected age group was individuals aged $>60$ years. ${ }^{18}$ This fact correlates with the higher incidence of chronic-degenerative diseases and polypharmacotherapy in this age group, evidencing the higher probability of mortality in the elderly. ${ }^{19}$

Predominant drugs suspected of triggering SJS and TEN were anticonvulsants, followed by analgesics and antibiotics. These data are in agreement with other studies that indicate anticonvulsants as the drugs most associated with the onset of SJS and TEN. ${ }^{20}$ To date, more than 100 drugs have been associated with SJS/TEN, including sulfonamides (metazolamide and acetazolamide), anticonvulsants (phenytoin, phenobarbital, carbamazepine and lamotrigine), NSAIDs (nonsteroidal anti-inflammatory drugs), xanthine oxidase inhibitors (allopurinol) and nevirapine (antiretroviral drug). ${ }^{21,22}$ However, presentation of these diseases depends on both genetic and environmental factors. ${ }^{15}$

Early recognition of reaction and withdrawal of the drug are fundamental therapeutic actions. ${ }^{23}$ However, it is observed in the sample studied that in only $21.7 \%$ of the medical charts analyzed there was a description of suspension of drug use. Thus, it is questioned whether such action had not actually been carried out or 
if it was not recorded in the medical chart. In any case, this is a primordial action and must be registered, both for medical follow-up and for the professional to be able to protect himself if the therapy is not effective and he/she is accused of malpractice. In hospitalized patients, main treatment measures were systemic antibiotic therapy, possibly after appearance of infectious complications, suspension of suspected drug and topical dressing in lesions. The most relevant complications presented were infection of lesions and sepsis (including septic shock), in addition to severe ocular lesions. Severity of systemic involvement by SJS is able to predict the likelihood of late eye lesions. ${ }^{24}$

Findings of this study are compatible with others reported by international studies: female predominance; considerable number of extensive lesions; antibiotics and anticonvulsants as triggers of the process in most cases. ${ }^{25,26}$

In this study, we observed that SCORTEN is not used as a prognostic factor in evaluation of patients affected by SJS and NET, since there are no specific records in medical charts of the referral hospital. SCORTEN is of paramount importance for establishing treatment measures, and is also an indicator of great relevance for subsequent comparative studies. ${ }^{13}$

Some SJS and TEN cases may not have been included in the database because they arose during hospitalization due to another underlying disease, and were not included in $\mathrm{SIH}$ as a reason for patient's hospitalization. On the other hand, records of hospitalizations at the referral hospital give us the possibility of defining a more specific profile of patients, although there are many fragilities in data of medical charts.
Limitations of this study lie in the fact that there is fragility in the registry of hospitalization of patients, both in $\mathrm{SIH}$ and in medical records of the referral hospital. Such fragility makes it difficult to construct a reliable and complete database on patients affected by such processes, which could be used to create protocols and standards in the treatment and prevention of these diseases, serving as a guide for professionals involved in the care of these patients. Improved registration and reporting methods will benefit both patients and health professionals involved, from those who are committed to patient care to those responsible for creating new drug formulations or altering existing ones.

\section{CONCLUSION}

In the period from 1999 to 2014, 86 SJS and TEN cases were recorded. There was a predominance of women and age range from 0 to 10 years. Drugs most commonly involved were anticonvulsants, antibiotics and analgesics. Differentiation between SJS and TEN was not adequately performed in medical records, number of records that documented withdrawal of drugs as conduct did not comply with the recommendation of suspension of drug use in all patients and there was no use of a prognostic score. On the other hand, number of records regarding incidence of SJS and TEN in hospitals in the Federal District does not allow us to draw a specific epidemiological profile. Data collected in this paper and conclusions obtained based on this information may contribute, albeit in part, to the enrichment of this literature. $\square$

\section{REFERENCES}

1. World Health Organization. International drug monitoring: the role of national centres. Rep Ser WHO 1972, n. 498. Geneva: World Health Organization; 1972.

2. Uetrecht J, Naisbitt DJ. Idiosyncratic adverse drug reactions: current concepts. Pharmacol Rev. 2013;65:779-808.

3. Upadhyaya SK, Raina RS, Sharma A, Thawani V, Dimari D. Carbamazepineinduced erythema multiforme major in an epileptic patient with bipolar affective disorder. J Pharmacol Pharmacother. 2012;3:202-4

4. Gaur S, Agnihotri R. Phenobarbital induced Stevens-Johnson syndrome in a child. Indian J Pharmacol. 2012;44:531-2.

5. Ensina LF, Fernandes FR, Di Gesu G, Malaman MF, Chavarria ML, Bernd LAG. Reações de Hipersensibilidade a Medicamentos - Parte III. Rev Bras Alerg Imunopatol. 2009;32:178-83.

6. Harr T, French LE. Toxic epidermal necrolysis and Stevens-Johnson syndrome. Orphanet J Rare Dis. 2010;5:39-42.

7. Oliveira A, Sanches M, Selores M. 0 espectro clínico da sindrome de stevens johnson e necrólise epidérmica tóxica. Acta Med Port. 2011;24:995-1002.

8. Dodiuk-Gad RP, Chung WH, Valeyrie-Allanore L, Shear NH. Stevens-Johnson Syndrome and Toxic Epidermal Necrolysis: An Update. Am J Clin Dermatol. 2015; 16:475-93.
9. Emerick MFB, Rodrigues MMT, Pedrosa DMAS, Novaes MRCG, Gottems LBD. Síndrome de Stevens-Johnson e Necrólise Epidérmica Tóxica em um hospital do Distrito Federal. Rev Bras Enferm. 2014;67:898-904.

10. Mockenhaupt M. The current understanding of Stevens-Johnson syndrome and toxic epidermal necrolysis, Expert Rev Clin Immunol. 2011;7:803-13.

11. Dodiuk-Gad RP, Olteanu C, Jeschke MG, Cartotto R, Fish J, Shear NH. Treatment of toxic epidermal necrolysis in North America. J Am Acad Dermatol. 2015;73:8767.e2.

12. Williams R, Hodge J, Ingram W. Indications for intubation and early tracheostomy in patients with Stevens-Johnson Syndrome and Toxic Epidermal Necrolysis. Am J Surg. 2016;211(4):684-688.

13. Fracaroli TS, Miranda LQ, Sodré JL, Chaves M, Gripp A. Necrólise epidérmica tóxica induzida pelo lansoprazol. An Bras Dermatol. 2013;88:117-20.

14. Whocc.no [internet]. Norway: Anatomical Therapeutic Chemical (ATC) Classification System. World Health Organization Collaborating Centre for Drug Statistics Methodology. 2016. [cited 2016 Sep 18]. Available from: http://www. whocc.no/atc_ddd_index/

15. Rufini S, Ciccacci C, Politi C, Giardina E, Novelli G, Borgiani P. Stevens-Johnson syndrome and toxic epidermal necrolysis: an update on pharmacogenetics studies 
in drug-induced severe skin reaction. Pharmacogenomics. 2015;16:1989-2002.

16. Cabral L, Diogo C, Riobom F, Teles L, Cruzeiro C. Necrólise Epidérmica Tóxica (Síndrome de Lyell): uma patologia para as Unidades de Queimados. Acta Med Port. 2004;17:129-40.

17. Blumenthal KG, Wickner PG, Lau JJ, Zhou L. Stevens-Johnson syndrome and toxic epidermal necrolysis: a cross-sectional analysis of patients in an integrated allergy repository of a large health care system. J Allergy Clin Immunol Pract. 2015;3(2):277-280.

18. Choon SE, Lai NM. An epidemiological and clinical analysis of cutaneous adverse drug reactions seen in a tertiary hospital in Johor, Malaysia. Indian J Dermatol Venereol Leprol. 2012;78:734-9.

19. Secoli SR. Polifarmácia: interações e reações adversas no uso de medicamentos por idosos. Rev Bras Enferm. 2010;63:136-40.

20. Kaur S, Dogra A. Toxic Epidermal Necrolysis due to concomitant use of lamotrigine and valproic acid. Indian J Dermatol. 2013;58:406.

21. Roujeau JC, Stern RS. Severe adverse cutaneous reactions to drugs. N Engl J Med. 1994;331:1272-85.

22. Wiffen PJ, Derry S, Moore RA, McQuay HJ. Carbamazepine for acute and chronic pain in adults. Cochrane Database Syst Rev. 2011;:CD005451

23. Garcia-Doval I, LeCleach L, Bocquet H, Otero XL, Roujeau JC. Toxic epidermal necrolysis and Stevens-Johnson syndrome: does early withdrawal of causative drugs decrease the risk of death? Arch Dermatol. 2000;136:323-7.

24. Yip LW, Thong BY, Lim J, Tan AW, Wong HB, Handa S, et al. Ocular manifestations and complications of Stevens-Johnson syndrome and toxic epidermal necrolysis: an Asian series. Allergy. 2007;62:527-31.

25. Borch JE, Andersen KE, Bindslev-Jensen C. The prevalence of acute cutaneous drug reactions in a Scandinavian university hospital. Acta Derm Venereol. 2006; 86:518-22.

26. Zaraa I, Jones M, Trojiet S, Cheikh Rouhou R, El Euch D, Mokni M, et al. Severe adverse cutaneous drug eruptions: epidemiological and clinical features. Int $\mathrm{J}$ Dermatol. 2011;50:877-80
MAILING ADDRESS:

Alice Garbi Novaes

SQS 309, Bloco K, apto 401

Asa Sul

70362-110 - Brasília, DF

Brazil

Email:alice_novaes@hotmail.com

How to cite this article: Arantes LB, Reis CS, Novaes AG, Carvalho MR, Göttems LBD, Novaes MRCG. Stevens-Johnson syndrome and toxic epidermal necrolysis: epidemiological and clinical outcomes analysis in public hospitals. An Bras Dermtatol. 2017;92(5):661-7. 